\title{
GRAPHENE OXIDE MICROCAPSULES (GOMs) WITH LINSEED OIL CORE VIA PICKERING EMULSION METHOD: EFFECT OF DISPERSE SPEED
}

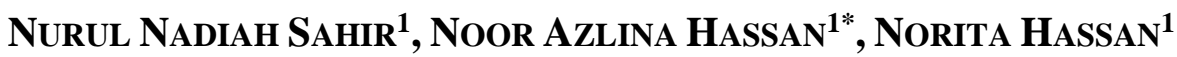 \\ AND NORHASNIDAWANI JOHARI ${ }^{2}$ \\ ${ }^{1}$ Department of Manufacturing and Materials Engineering, \\ International Islamic University Malaysia, \\ Jalan Gombak, 53100 Kuala Lumpur, Malaysia \\ ${ }^{2}$ Department of Mechanical Precision Engineering, \\ Malaysia-Japan International Institute of Technology, \\ UTM, 54100 Kuala Lumpur, Malaysia \\ *Corresponding author: noorazlina_hassan@iium.edu.my
}

(Received: 25th March 2020; Accepted: $3^{\text {rd }}$ September 2020; Published on-line: $4^{\text {th }}$ January 2021)

\begin{abstract}
Graphene oxide microcapsules (GOMs) have been prepared through Pickering emulsion method by varying the disperse speed to study its effect on the GOM's size. The GOMs were characterized through phase separation observation, polarized optical microscope (POM), and particle size analyser (PSA). Phase separation observation showed more viscous and cloudy emulsion was produced when the disperse speed was increased. After 24 hours, only $800 \mathrm{rpm}$ emulsion did not show any phase separation. POM characterization depicted that increasing the emulsification energy led to the finer emulsion with the $1200 \mathrm{rpm}$ sample showing the smallest microcapsule size of around 8 $\mu \mathrm{m}$. However, PSA analysis suggested that although the disperse speed controls the GOMs size, the amount of GO in the emulsion plays an important role for the microcapsule to maintain its stability. Emulsion produced at $800 \mathrm{rpm}$ possesses satisfactory stability with GOMs diameter of $11.15 \mu \mathrm{m}$. The result also suggested that graphene oxide encapsulated linseed oil may act as a promising candidate for healing microcapsules in a self-healing coating system.
\end{abstract}

ABSTRAK: Mikrokapsul graphene oksida (GOMs) telah dihasilkan melalui kaedah emulsifikasi Pickering dengan memvariasikan tenaga pengemulsi untuk mengkaji kesannya terhadap saiz GOMs. GOMs dicirikan melalui pemerhatian pemisahan fasa, mikroskop optik polarisasi (POM) dan penganalisis saiz zarah (PSA). Pemerhatian pemisahan fasa menunjukkan emulsi yang lebih likat dan keruh dihasilkan apabila kelajuan pengemulsi meningkat. Selepas 24 jam, hanya emulsi $800 \mathrm{rpm}$ tidak menunjukkan pemisahan fasa. Pencirian POM meunjukkan bahawa peningkatan tenaga pengemulsi menghasilkan emulsi yang lebih halus dengan sampel $1200 \mathrm{rpm}$ menunjukkan saiz mikrokapsul terkecil, sekitar $8 \mu \mathrm{m}$. Walau bagaimanapun, analisis PSA mencadangkan bahawa walaupun kelajuan pengemulsi mengawal saiz GOMs, jumlah GO dalam emulsi memainkan peranan penting untuk mengekalkan kestabilan mikrokapsul. Emulsi yang dihasilkan pada $800 \mathrm{rpm}$ mempunyai kestabilan yang memuaskan dengan purata saiz GOMs sekitar $11.15 \mu \mathrm{m}$. Berdasarkan dapatan kajian, graphene oksida yang terkandung minyak biji rami boleh menjadi salah satu mikrokapsul penyembuh dalam sistem cat auto-sembuh.

KEYWORDS: graphene oxide; Pickering emulsion; linseed oil; microcapsules 


\section{INTRODUCTION}

Graphene oxide (GO), is the most important derivative of graphene. GO is a twodimensional material that consists of partially broken $\mathrm{sp}^{2}$-bonded carbon networks. Phenol, hydroxyl and epoxide groups occupy the basal planes of the sheet and carboxylic acid groups attached to the edges make the GO sheet possess the amphiphilic property and be readily dispersed in water or any solvent [1]. Although the thickness of the GO sheet is only in nanometers, its excellent impermeability indicates GO possesses a superior barrier property [2]. Many researchers utilize this advantage by incorporating the GO sheets into a protective coating for metals, polymer membranes for gas barrier films, and water treatment applications [3-5]. Di et al. found that GO incorporated coating exhibits good anti-corrosion properties by delaying the migration of corrosive species to the underlying substrate, while Ammar et al. reported that the gas barrier property of GO infused polymer increased dramatically $[6,7]$.

GO has also been utilized in liquid crystals (LC) for various applications such as supercapacitors, sensors, optical-switching devices, and also graphene oxide-based foam and aerogel for sound absorbers [8-11]. Graphene oxide liquid crystals (GOLCs), a highly anisotropic fluid consist of the long-range crystal-like ordering of GO. This latest class of 2D nanomaterials possesses colloidal liquid crystallinity contributed by their intrinsic disclike shape anisotropy [12]. As reported by Abedin et al., water is the most reported media for GOLC due to the extensive hydrogen bonding [13]. The colloidal system containing 2D GO sheets can be effectively aligned by external shear force because of their self-alignment ability in nematic phases. Jalili et al. suggested that this behaviour makes the GOLC suitable to synthesize macroscopic objects such as fibers, film, membranes, and foams [14].

This paper reports on the utilization of GOLCs to encapsulate the healing agent as the potential candidate for a healing agent reservoir in a self-healing coating. The graphene oxide microcapsules (GOMs) were synthesized through the Pickering emulsion method. Pickering emulsion is an emulsion of any type, whether oil-in-water $(\mathrm{O} / \mathrm{W})$ or water-in-oil (W/O) stabilized by solid particles [15]. The interesting differences between the Pickering emulsions compared to the classical emulsion are the absence of surfactant, superior stability, and low toxicity [16]. By employing GO as the stabilizer in the Pickering emulsion system, it is possible to tailor microscopic capsules due to its surface flexibility and strong van der Waals force between individual GO sheets [17]. The excellent barrier properties of GO sheets also make them suitable candidates to store the healing agent in self-healing coatings where the impermeability to diffusion is needed [18].

The core material for the GOMs, linseed oil (LO), is the most popular seed extract for corrosion inhibition and was also reported as a hydrophobic agent [19]. It is a type of drying oil that undergoes oxidative polymerization if it is exposed to the atmosphere [20]. Linseed oil has been encapsulated within various materials including poly(urea) formaldehyde (PUF), ethylcellulose and poly(methyl methacrylate) for self-healing coating application [21-23]. In this research, GOMs is produced by using only GO sheets and linseed oil with the help of high shear stirring. The disperse speed is varied to study their effect on the microcapsule's size. The optimum shear speed for the fabrication of GOMs is proposed for their application in water-based self-healing coating for future works.

\section{MATERIALS AND METHOD}

GOMs were synthesized through the Pickering emulsion method as discussed by Li et al. [24]. The disperse speed (rpm) is the parameter that affects the microcapsule's size. Briefly, GOMs were prepared by adding 0.37g linseed oil (Sigma Aldrich, $0.93 \mathrm{~g} / \mathrm{ml}$ ) into 
the $5 \mathrm{ml}$ graphene oxide solution (Hummer method, Graphene Supermarket ${ }^{\mathrm{TM}}, 3.7 \mathrm{mg} / \mathrm{ml}$ ) followed by mixing it with an overhead stirrer for 10 minutes. The disperse speed (rpm) was varied (400, 800, 1200, 1600, 2000, and $2400 \mathrm{rpm}$ ) while maintaining the same amount of GO concentration. The emulsion formed is then transferred to $7 \mathrm{ml}$ polyethylene vials.

The resultant emulsions were characterized through phase separation observation and polarized optical microscope (POM) (model: LEXT OLS4100). The emulsions formed were viscous and not suitable for optical microscope characterization. To capture the image clearly, the emulsions were diluted with deionized water with a dilution factor of 3 . Then, they were dropped onto the surface of a glass slide and characterized immediately. The GOMs size is recorded based on the POM images. The coefficient of variation, $C v$ of the GOMs was calculated by using the Eq. (1) below:

$$
\text { Coefficient of Variation }(\mathrm{Cv})=\frac{\text { standard deviation }}{\text { mean size of GOMS }}
$$

Droplet size distribution for oil-in-water emulsions was analyzed by Particle size analyzer (PSA) (model: Malvern Zetasizer Nano). The refractive index is set to 1.4795 (linseed oil).

\section{RESULTS AND DISCUSSION}

\subsection{Phase Separation Observation}

To study the effect of emulsification energy on the properties of the emulsions formed, the disperse speed was varied from 400 to $2400 \mathrm{rpm}$. Figure 1 shows the digital images of the emulsions right after the synthesis. Emulsion in Fig. 1(b) to 1(f) showed a successful emulsification process based on the cloudy appearance. Emulsion tends to appear cloudy because the light is scattered off the phase interphases between the oil and water components [25]. The visible cloudiness is also an indication that the GOMs produced are in micronranges [26]. As reported by Kim et al. GO sheets can stabilize the linseed oil in water as they could behave like a colloidal surfactant [27].

By increasing the mixing speed, the emulsion is observed to be more viscous. This is also another indication that the size of the GOMs is reduced and the amount of the GOMs is increased, which in turn increases the interfacial area. An early study by Thompson et al. found that the increase in the interfacial area led to an increase in interfacial viscosity effects and also an increase in hydrodynamic interactions [28]. Gohtani \& Yoshii also reported the same phenomenon where the emulsion diameter was found to significantly affect the emulsion viscosity, in which the viscosity increased as the emulsion diameter decreased [29].

Emulsions as shown in Fig. 1(a), stirred with low rpm, showed not all solid particles and oil participate in the emulsification process. This can be proven by the formation of two different phases with the oil phase occupying the upper part of the mixture. The dark brown colour of the lower water phase shows that there is a large amount of GO left in the water. The emulsification energy supplied for emulsion (a) is not sufficient enough to fully emulsify the linseed oil. As the disperse speed increased, the colour of the emulsion becomes lighter, as depicted by the colour bar in Fig. 1. 


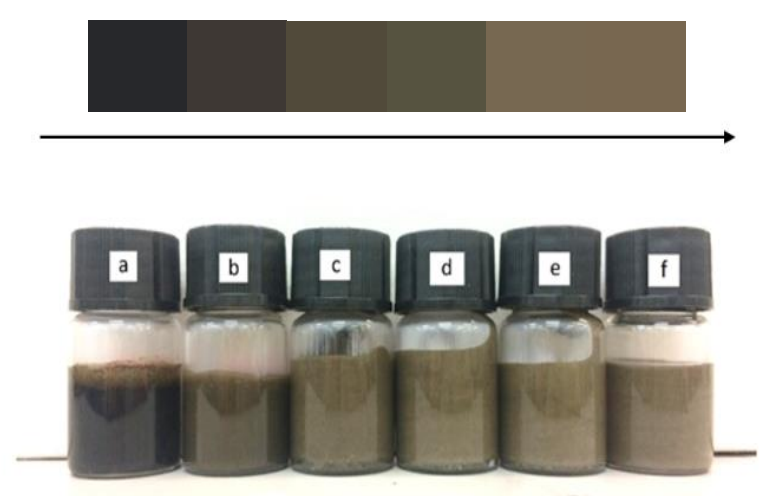

Fig. 1: Digital image of the emulsions formed with different rotational shear speed a) $400 \mathrm{rpm}$, b) $800 \mathrm{rpm}$, c) $1200 \mathrm{rpm}$, d) $1600 \mathrm{rpm}$, e) $2000 \mathrm{rpm}$, and f) $2400 \mathrm{rpm}$.

Based on Fig. 2, the emulsion prepared at $800 \mathrm{rpm}$ is the only sample that showed no phase separation layer, while destabilization occurred to the rest of the emulsion. The bottom part was occupied by the continuous phase, while the top region or the creaming part was rich with the GOMs. It was postulated that the destabilization happened due to an insufficient amount of GO sheets to stabilize the GOMs.

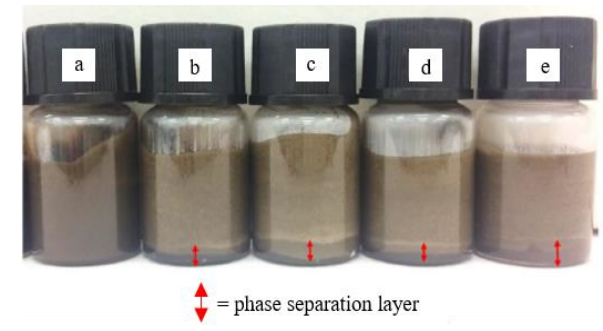

Fig. 2: Digital images of emulsions containing GOMs prepared with varied disperse speed monitored after 24 hours, a) $800 \mathrm{rpm}$, b) $1200 \mathrm{rpm}$, c) $1600 \mathrm{rpm}$, d) $2000 \mathrm{rpm}$, and e) $2400 \mathrm{rpm}$.

\subsection{Polarized Optical Microscope (POM) Analysis}

POM characterization was done directly after the emulsification process. The images in Fig. 3 showed that GOMs were present in all samples, based on the existence of bright shining halos around the emulsion droplets. Under normal light, the milky emulsion was difficult to observe. Therefore polarized light was needed. The presence of shining halos around the oil droplets suggested the GO sheets assembled themselves at the liquid-liquid interface. The distinct shining halos observed indicate the emulsion was isotropic except for the bright GO shells. The birefringence has a cross-shape that originates from the presence of oil droplets in the anisotropic colloidal structure [30]. Note that emulsions formed without GO do not behave in this way due to the fact that they are optically isotropic, which means they cannot emit the liquid crystal behaviour [31]. The liquid crystal structure is formed when GO align themselves around the oil droplets and these molecularly ordered GO sheets are what gave off the birefringence property, which is a typical fingerprint of liquid crystals [32]. Therefore, it shows that GOMs were successfully obtained.

GO sheets tend to localize between the liquid-liquid interface to minimize the interfacial energy between two immiscible liquids (linseed oil and water). The high surface area of the 
GO sheets enables them to wrap around the linseed oil droplets. The wettability of GO also made this possible. The wettability test done by Panda et al. showed that GO obtained through Hummer method possess the contact angle $\left(\theta_{\mathrm{w}}\right)$ of less than $90^{\circ}$, which is around $46.5^{\circ}$ [33]. The test involves the measuring of the contact angle between the GO film and water. This indicates that GO is partially hydrophilic and prone to stabilize oil-in-water $(\mathrm{O} / \mathrm{W})$ emulsion due to its particle surface resides more in water than in oil. This is in line with our experimental results. GOMs are readily dispersed in water, implying the formation of an $\mathrm{O} / \mathrm{W}$ emulsion system with linseed oil droplets as the dispersed phase and GO solution making up the continuous phase.

Figure 3 also showed the images of GOMs with uneven size distribution and as the shear speed was increased, finer and more even microcapsule sizes were produced. The average size and coefficient of variation $\left(\mathrm{C}_{\mathrm{v}}\right)$ for each emulsion listed in Table 1 also supported the finding. As the speed increased, the value of $\mathrm{C}_{\mathrm{v}}$ decreased, indicating a low variation of droplets diameter [34]. This is in good agreement with Chevalier \& Bolzinger suggesting that in Pickering emulsion, a high energy emulsification process can break the oil into small droplets resulting in finer emulsions [35].

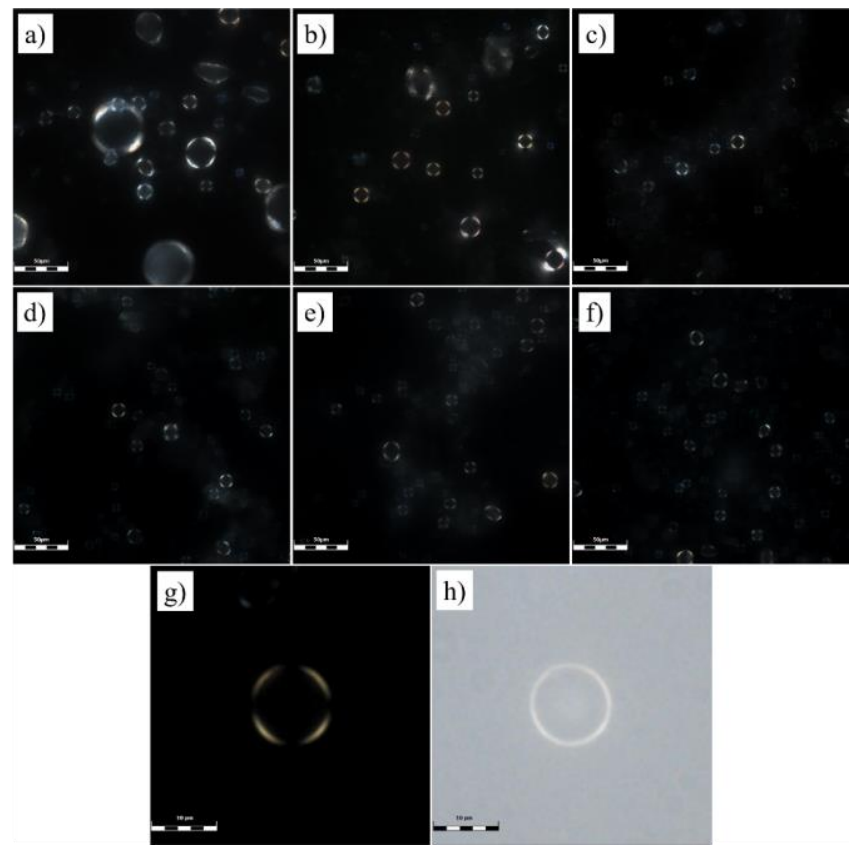

Fig. 3: Image of the emulsion under a polarized optical microscope, a) $400 \mathrm{rpm}, \mathrm{b}$ ) $800 \mathrm{rpm}$, c) $1200 \mathrm{rpm}$, d) $1600 \mathrm{rpm}$, e) $2000 \mathrm{rpm}$, f) $2400 \mathrm{rpm}$, g) single GOM under polarized light and h) single GOM under optical microscope.

Table 1: Average size and $\mathrm{C}_{\mathrm{v}}$ value for each emulsion

\begin{tabular}{ccc}
\hline $\begin{array}{c}\text { Disperse Speed } \\
{[\mathbf{r p m}]}\end{array}$ & $\begin{array}{c}\text { Average Size } \\
{[\boldsymbol{\mu m}]}\end{array}$ & $\begin{array}{c}\text { Coefficient of } \\
\text { Variation }\left[\mathbf{C}_{\mathbf{v}}\right]\end{array}$ \\
\hline 400 & 20.36 & 0.73 \\
800 & 11.15 & 0.34 \\
1200 & 8.57 & 0.31 \\
1600 & 8.33 & 0.26 \\
2000 & 8.02 & 0.29 \\
2400 & 8.11 & 0.24 \\
\hline
\end{tabular}

To further understand the GOMs formation, Fig. 4 depicts the schematic representation of the preparation process and encapsulation mechanism. An overhead stirrer breaks the oil 
into small droplets (Fig. 4b) followed by the stabilization of the oil droplets by hydrophilic GO sheets that assembled themselves at the oil-liquid interface (Fig. 4c). Figure 4(d) showed the desired final product that was called graphene oxide encapsulated linseed oil, or graphene oxide Pickering emulsion or GOMs.

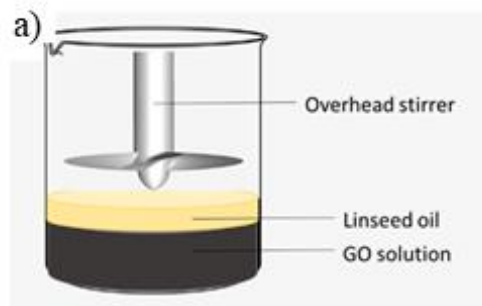

c) water

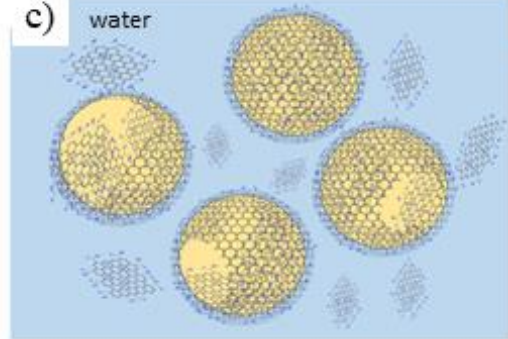

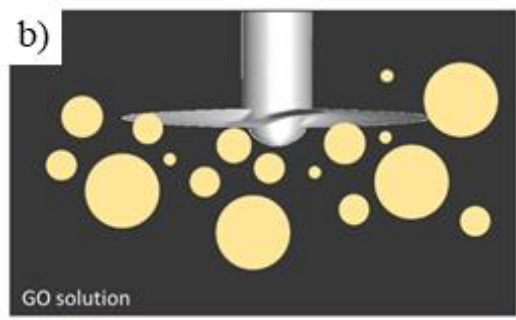

d) water

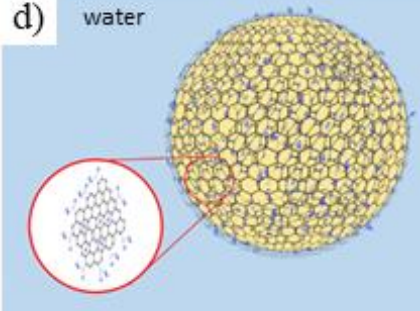

Fig. 4: Encapsulation process, a) Emulsion preparation, b) Breaking of linseed oil into small droplets by the propeller, c) GO sheets assembled themselves around the linseed oil droplets, d) stabilized Pickering emulsion (GOMs).

It needs to be noted that a small microcapsule with an even size distribution is more favourable to be used in self-healing coatings. The incorporation of the bigger container into the coating can disrupt the barrier properties and reduce the coating resistance [36]. Although increasing the shear speed does decrease the microcapsule's size, there is no significant size reduction observed for the GOMs when the disperse was higher than 1200 rpm. This might be due to the oil droplets reaching their maximum limit to further break down into smaller droplets and a limited amount of GO sheets to stabilize them.

\subsection{Particle Size Analyzer (PSA) Analysis}

Figure 5 displays the size distribution for all emulsions. As the size of the GOMs did not change much when they were prepared at $1200 \mathrm{rpm}$ and above, only four emulsions were characterized. In contrast with POM results, the result obtained from particle size analyzer showed a different trend where the droplet size increased as the disperse speed was increased. The PSA result showed GOMs prepared with the disperse speed of $400 \mathrm{rpm}$ exhibits the smallest size compared to others but its POM result displayed the emulsion is only partially stabilized. It should be noted that the sample taken for PSA characterization is from the continuous phase and not from the creaming part.

The PSA characterization was done after 24 hours which allowed the emulsions to settle down. This phenomenon explains why the increasing trend happened. The oil droplets were able to maintain their size for a while but after a few hours, they started to coalesce due to lack of stabilizing moieties. Increasing the shear speed breaks the oil into small droplets, resulting in the increasing amount of droplets present in the continuous phase. This will also cause the surface area of the droplets to increase, thus, requiring more GO particles to wrap the linseed oil droplet and form a stable emulsion. This result is also supported by the phase separation observation discussed in section 3.1 previously. It is worth mentioning that other stabilizers or surfactants could be added to hold the GOMs structure to maintain their sizes 
prior to the PSA characterization. However, POM analysis may give more accurate and reliable results as the GOMs used in this study only utilized GO sheets as a stabilizer.
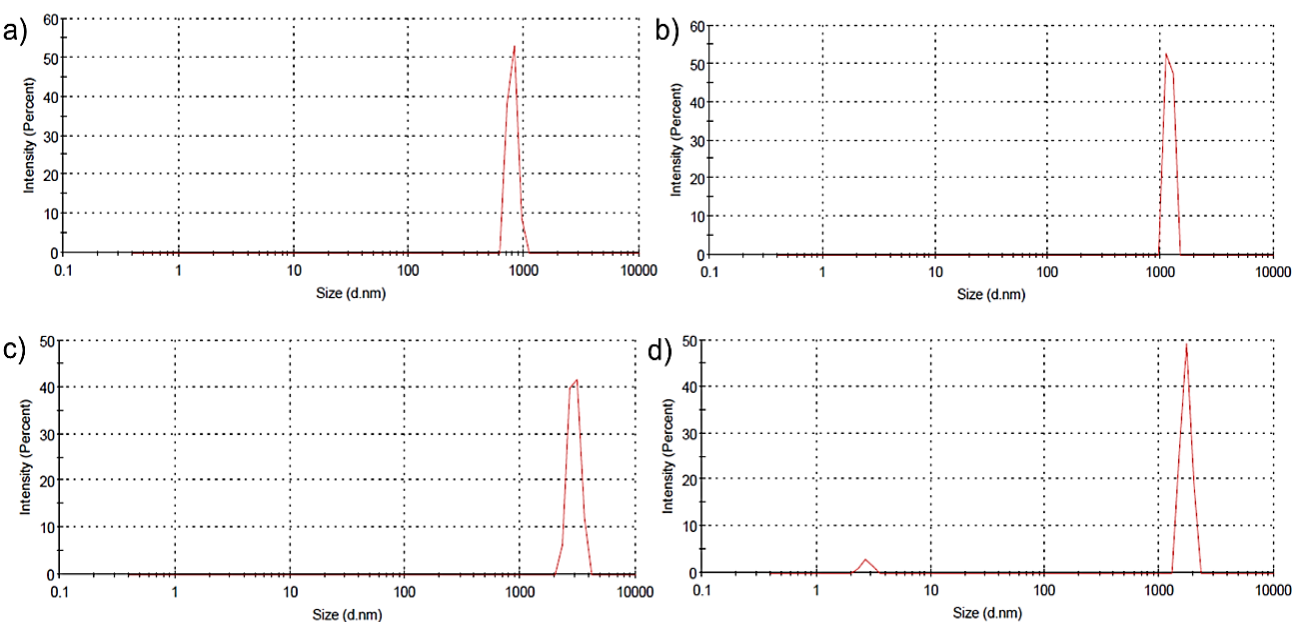

Fig. 5: The droplet size distribution of GOMs, a) $400 \mathrm{rpm}$, b) $800 \mathrm{rpm}$, c) $1200 \mathrm{rpm}$ and d) $1600 \mathrm{rpm}$.

This finding implied that the disperse speed and stabilizing moieties go hand in hand and controlling only one parameter is not enough to produce stable GOMs. Studies done by Tsabet \& Fradette also supported the above-mentioned observations. They suggested that by increasing the energy will promote droplet generation and produce a larger interface, and the amount of stabilizing particles also need to be increased to cover and stabilize the interface [37].

Figure 6 displays the GOMs size comparison obtained through POM and PSA. There are some discrepancies between POM and PSA results as the POM measures the GOMs diameter which includes the GO shell thickness, while PSA measures only the linseed oil droplet's diameter. Nevertheless, the increasing size pattern that comes from the PSA analysis needs to be taken into account and cannot be ignored. By comparing POM and PSA analysis, $800 \mathrm{rpm}$ is the preferable speed for the preparation of GOMs with satisfied microcapsule size. This was further supported by the phase separation observation discussed in section 3.1, where only GOMs prepared at $800 \mathrm{rpm}$ maintained its stability.

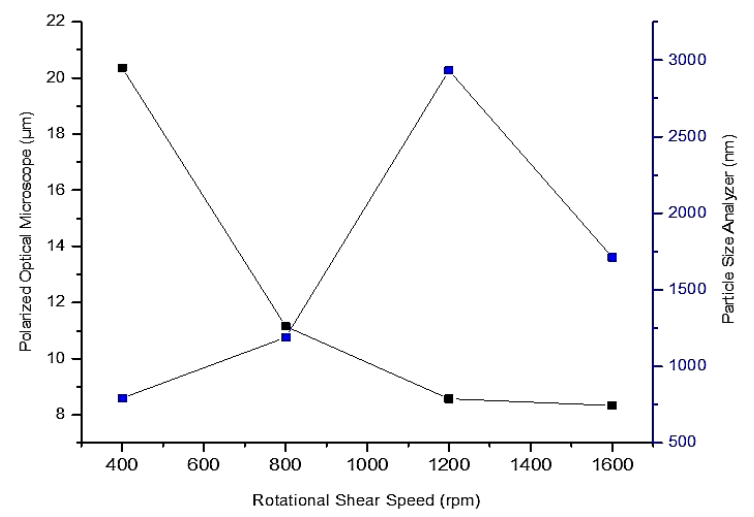

Fig. 6: Average size distribution based on POM images and PSA of the emulsions. 


\section{CONCLUSION}

GOMs were successfully produced through the Pickering emulsion method. The POM analysis showed the disperse speed affects the size of the produced GOMs, where insufficient emulsification energy led to a partially stabilized emulsion. However, PSA analysis suggests the GO-HMs size depends on both disperse speed and the amount of stabilizing moieties. Controlling only one parameter is not sufficient to produce fine and stable emulsions. Although POM images showed that the disperse speed of $1200 \mathrm{rpm}$ produced the smallest diameter of GOMs (around $8 \mu \mathrm{m}$ ), considering the PSA pattern and phase separation observations, $800 \mathrm{rpm}$ is chosen as the ideal processing speed to produce GOMs with satisfactory size $(11.15 \mu \mathrm{m})$ and stability. Linseed oil is effectively wrappedup by GO in the oil-in-water emulsion system based on the presence of shining halos around the oil droplets. This finding also showed GO is capable to encapsulate healing agents and may be a suitable candidate for microcapsules to be used in waterborne self-healing coating.

\section{ACKNOWLEDGEMENT}

This work was funded by RIGS17-107-0682 and FRGS19-058-0666 research grants. The authors would like to acknowledge the Kuliyyah of Engineering, International Islamic University Malaysia (IIUM), Ministry of Higher Education (MOHE), Malaysia and every party involved both directly and indirectly in this work.

\section{REFERENCES}

[1] Shao, JJ, Lv W, Yang QH. (2014) Self-assembly of graphene oxide at interfaces. Advanced Materials, 26(32): 5586-5612.

[2] Wu J, Huang G, Li H, Wu S, Liu Y, Zheng J. (2013) Enhanced mechanical and gas barrier properties of rubber nanocomposites with surface functionalized graphene oxide at low content. Polymer, 54(7): 1930-1937.

[3] Ramezanzadeh B, Niroumandrad S, Ahmadi A, Mahdavian M, Moghadam MM. (2016) Enhancement of barrier and corrosion protection performance of an epoxy coating through wet transfer of amino functionalized graphene oxide. Corrosion Science, 103: 283-304.

[4] Bandyopadhyay P, Park WB, Layek RK, Uddin ME, Kim NH, Kim HG, Lee JH. (2016) Hexylamine functionalized reduced graphene oxide/polyurethane nanocomposite-coated nylon for enhanced hydrogen gas barrier film. Journal of Membrane Science, 500: 106-114.

[5] Wang J, Zhang P, Liang B, Liu Y, Xu T, Wang L, Cao B, Pan K. (2016). Graphene oxide as an effective barrier on a porous nanofibrous membrane for water treatment. ACS Applied Materials \& Interfaces, 8(9): 6211-6218.

[6] Di H, Yu Z, Ma Y, Li F, Lv L, Pan Y, Lin Y, Liu Y, He Y. (2016) Graphene oxide decorated with $\mathrm{Fe}_{3} \mathrm{O}_{4}$ nanoparticles with advanced anticorrosive properties of epoxy coatings. Journal of the Taiwan Institute of Chemical Engineers, 64: 244-251.

[7] Ammar A, Al-Enizi AM, AlMaadeed MA, Karim A. (2016) Influence of graphene oxide on mechanical, morphological, barrier, and electrical properties of polymer membranes. Arabian Journal of Chemistry, 9(2): 274-286.

[8] Wang B, Liu J, Zhao Y, Li Y, Xian W, Amjadipour M, MacLeod J, Motta N. (2016) Role of graphene oxide liquid crystals in hydrothermal reduction and supercapacitor performance. ACS Applied Materials \& Interfaces, 8(34): 22316-22323.

[9] Choi SJ, Yu H, Jang JS, Kim MH, Kim SJ, Jeong HS, Kim ID. (2018) Nitrogen-Doped Single Graphene Fiber with Platinum Water Dissociation Catalyst for Wearable Humidity Sensor. Small, 14(13): 1703934.

[10] Shen TZ, Hong SH, Song JK. (2014) Electro-optical switching of graphene oxide liquid crystals with an extremely large Kerr coefficient. Nature Materials, 13(4): 394-399. 
[11] Oh JH, Kim J, Lee H, Kang Y, Oh IK. (2018) Directionally antagonistic graphene oxidepolyurethane hybrid aerogel as a sound absorber. ACS Applied Materials \& Interfaces, 10(26): 22650-22660.

[12] Narayan R, Kim JE, Kim JY, Lee KE, Kim SO. (2016) Graphene oxide liquid crystals: discovery, evolution and applications. Advanced Materials, 28(16): 3045-3068.

[13] Abedin MJ, Gamot, TD, Martin ST, Ali M, Hassan KI, Mirshekarloo MS, Majumder M. (2019) Graphene Oxide Liquid Crystal Domains: Quantification and Role in Tailoring Viscoelastic Behavior. ACS Nano, 13(8): 8957-8969.

[14] Jalili R, Aboutalebi SH, Esrafilzadeh D, Konstantinov K, Moulton SE, Razal JM, Wallace GG. (2013) Organic solvent-based graphene oxide liquid crystals: A facile route toward the next generation of self-assembled layer-by-layer multifunctional 3D architectures. ACS Nano, 7(5): 3981-3990.

[15] Chevalier Y, Bolzinger MA, Briançon S. (2015) Pickering emulsions for controlled drug delivery to the skin. In Percutaneous Penetration Enhancers Chemical Methods in Penetration Enhancement (pp. 267-281). Springer, Berlin, Heidelberg.

[16] Wu J, Ma GH. (2016) Recent studies of Pickering emulsions: particles make the difference. Small, 12(34): 4633-4648.

[17] Teo GH, Ng YH, Zetterlund PB, Thickett SC. (2015) Factors influencing the preparation of hollow polymer-graphene oxide microcapsules via Pickering miniemulsion polymerization. Polymer, 63: 1-9.

[18] Ullah H, Azizli, KA, Man ZB, Ismail MBC, Khan MI. (2016) The potential of microencapsulated self-healing materials for microcracks recovery in self-healing composite systems: A review. Polymer Reviews, 56(3): 429-485.

[19] Montemor MF. (Ed.) (2015). Smart composite coatings and membranes: Transport, structural, environmental and energy applications. Elsevier.

[20] Hughes AE, Mol JM, Zheludkevich ML, Buchheit RG. (2016) Active protective coatings. Active Protective Coatings: New-Generation Coatings for Metals, Springer Series in Materials Science, vol. 233. ISBN 978-94-017-7538-0. Springer Science+ Business Media Dordrecht.

[21] Çömlekçi GK, Ulutan S. (2019) Acquired self-healing ability of an epoxy coating through microcapsules having linseed oil and its alkyd. Progress in Organic Coatings, 129: 292-299.

[22] Abbaspoor S, Ashrafi A, Abolfarsi R. (2019) Development of self-healing coatings based on ethyl cellulose micro/nano-capsules. Surface Engineering, 35(3): 273-280.

[23] Navarchian AH, Najafipoor N, Ahangaran F. (2019) Surface-modified poly (methyl methacrylate) microcapsules containing linseed oil for application in self-healing epoxybased coatings. Progress in Organic Coatings, 132: 288-297.

[24] Li J, Feng Q, Cui J, Yuan Q, Qiu H, Gao S, Yang J. (2017) Self-assembled graphene oxide microcapsules in Pickering emulsions for self-healing waterborne polyurethane coatings. Composites Science and Technology, 151: 282-290.

[25] Afshar Ghotli R, Raman AA, Ibrahim S, Baroutian S. (2013) Liquid-liquid mixing in stirred vessels: A review. Chemical Engineering Communications, 200(5): 595-627.

[26] Yamashita Y, Miyahara R, Sakamoto K. (2017) Emulsion and emulsification technology in Cosmetic Science and Technology (1st edition), Elsevier, pp 489-506.

[27] Kim J, Cote LJ, Kim F, Yuan W, Shull KR, Huang J. (2010) Graphene oxide sheets at interfaces. Journal of the American Chemical Society, 132(23): 8180-8186.

[28] Thompson DG, Taylor AS, Graham DE. (1985) Emulsification and demulsification related to crude oil production. Colloids and Surfaces, 15: 175-189.

[29] Gohtani S, Yoshii H. (2018) Microstructure, composition, and their relationship with emulsion stability. In Food Microstructure and Its Relationship with Quality and Stability (pp. 97-122). Woodhead Publishing.

[30] Lapointe CP, Mason TG, Smalyukh, II. (2009) Shape-controlled colloidal interactions in nematic liquid crystals. Science, 326(5956): 1083-1086.

[31] Wan W, Zhao Z, Hughes TC, Qian B, Peng S, Hao X, Qiu J. (2015) Graphene oxide liquid crystal Pickering emulsions and their assemblies. Carbon, 85: 16-23. 
[32] Andrienko,D. (2018) Introduction to liquid crystals. Journal of Molecular Liquids, 267: 520541.

[33] Panda D, Nandi A, Datta SK, Saha H, Majumdar S. (2016) Selective detection of carbon monoxide $(\mathrm{CO})$ gas by reduced graphene oxide $(\mathrm{rGO})$ at room temperature. RSC advances, 6(53): 47337-47348.

[34] Low LE, Wong SK, Tang SY, Chew CL, De Silva HA, Lee JMV, Hoo CH, Kenrick K. (2019) Production of highly uniform Pickering emulsions by novel high-intensity ultrasonic tubular reactor (HUTR). Ultrasonics sonochemistry, 54: 121-128.

[35] Chevalier Y, Bolzinger MA. (2013) Emulsions stabilized with solid nanoparticles: Pickering emulsions. Colloids and Surfaces A: Physicochemical and Engineering Aspects, 439: 23-34.

[36] Borisova D, Akçakayıran D, Schenderlein M, Möhwald H, Shchukin DG. (2013) Nanocontainer-Based Anticorrosive Coatings: Effect of the Container Size on the SelfHealing Performance. Advanced Functional Materials, 23(30): 3799-3812.

[37] Tsabet E, Fradette L. (2015) Effect of processing parameters on the production of Pickering emulsions. Industrial \& Engineering Chemistry Research, 54(7): 2227-2236. 